\title{
Salivary Gland Cytology: Histological Correlation and Clinicopathological Analysis- A Five Year Study At a Tertiary Care Hospital
}

\author{
Dr. Supriya $\mathrm{P}^{1^{*}}$, Dr. Parinitha $\mathrm{SS}^{2}$
}

${ }^{1}$ Assistant professor, Department of Pathology, Yenepoya Medical College, Deralakatte, Mangalore, Karnataka, India

${ }^{2}$ Professor, Department of Pathology, SDM College of Medical sciences and Hospital, Dharwad, Karnataka, India

DOI: $10.36348 /$ sjpm.2020.v05i03.002
*Corresponding author: Dr. Supriya

| Received: 22.02.2020 | Accepted: 02.03.2020 | Published: 06.03.2020

Abstract

Background: Fine Needle Aspiration Cytology (FNAC) is worldwide accepted, inexpensive, minimally invasive and very accurate method today especially in commonly encountered clinical problems like salivary gland lesions which range from non-neoplastic lesions like inflammation, cysts, and commonest benign tumours like pleomorphic adenoma to malignant lesions of variable malignant potential. FNAC is major diagnostic tool and is of great relevance in head and neck lesions, including major salivary glands as they are easily accessible target sites. The aim of this study was to evaluate spectrum of salivary gland lesions with their clinical presentations and to study the cytomorphological features of various salivary gland lesions, and to evaluate its sensitivity and specificity of FNAC in salivary gland lesions whenever histopathology was available. Material and Methods: A total of 150 cases of salivary gland lesions were analysed both retrospectively and prospectively from January 2010- December 2015 at Department of Pathology, of a tertiary care medical college Hospital. Cyto-histopathological correlation was interpreted wherever available. Results: In the 150 cases thus analysed, the male to female ratio was 1.14:1. Parotid gland was involved in $73.34 \%$, submandibular gland in $23.33 \%$, and other minor salivary glands in $3.33 \%$ of patients. There were $57.33 \%$ cases of neoplastic lesions and $42.67 \%$ cases of non-neoplastic lesions. Chronic sialadenitis $(22.67 \%)$ was the commonest non neoplastic lesion. Pleomorphic adenoma (40.67\%) was the commonest benign neoplasm and Mucoepidermoid carcinoma (9.33\%) was the commonest malignant neoplasm. The overall sensitivity, specificity and diagnostic accuracy of FNAC for salivary gland lesions were $93.48 \%, 100 \%$ and $94.23 \%$, respectively. Conclusion: Fine-needle aspiration cytology is a very useful diagnostic tool for superficial palpable tumors of salivary glands. It has high rates of sensitivity, specificity, positive predictive value in diagnosing salivary gland lesions and hence a valuable tool in the diagnosis and management of patients.

Keywords: Fine-needle aspiration cytology, salivary gland tumors, cyto-histopathological correlation, sensitivity, specificity, diagnostic accuracy.

Copyright @ 2020: This is an open-access article distributed under the terms of the Creative Commons Attribution license which permits unrestricted use, distribution, and reproduction in any medium for non-commercial use (NonCommercial, or CC-BY-NC) provided the original author and sources are credited.

\section{INTRODUCTION}

Fine-needle aspiration cytology (FNAC) as a diagnostic procedure is well established and used to evaluate palpable lesions. It is the initial investigative technique applied to establish a diagnosis before any surgical intervention. It is widely used,safe and relatively non traumatic procedure that can immediately provide important information [1-3]. It is easily applicable for locations such as the salivary glands, in particular the major salivary glands and to a lesser extent the minor salivary glands [4].The lesions of salivary glands are commonly encountered clinical problems and range from non-neoplastic lesions like inflammation (sialadenitis) and cysts, commonest benign tumour like pleomorphic adenoma to malignant lesions of variable malignant potential [5]. Fine needle aspiration cytology (FNAC) of the salivary glands is an accepted, sensitive and specific technique in the diagnosis of both neoplastic and non-neoplastic lesions $[2,6]$. Lesions of the salivary glands frequently are evaluated by this technique and the usefulness of salivary gland FNA relates to the fact that it is easy to perform, minimally invasive, smear evaluation is immediate, and the procedure can be repeated several times to obtain more tissue for diagnosis $[1,2,3]$. The diagnostic accuracy of FNAC of salivary glands reported varies between $86 \%$ to $98 \%$ [2,4]. The sensitivity ranges from $62 \%$ to $97.6 \%$ and specificity is higher from $94.3 \%$ to $100 \%[1,2,4,11,12]$. The objective of this study was to study the spectrum of various salivary gland lesions on FNAC, evaluate the 
sensitivity and specificity in various salivary gland neoplasms, which helps in the appropriate therapeutic management.

\section{MATERIAL AND METHODS}

The present study has been carried out in the Department of Pathology; of a tertiary care medical college hospital. The study group comprised both prospective and retrospective cases of salivary gland lesions from January 2010 to December 2015. Among the prospective study, cases were included from June 2013 to December 2015 of all salivary gland swelling attending surgical OPD/admitted in inpatientwards. In the retrospective study all cases from January 2010 to May 2013 with all data, cytology and histopathology slides collected from archives as well as the medical record section of all diagnosed cases of salivary gland lesions was studied. A thorough history, local and systemic examination was made regarding the general condition of the patient and regions involved. After explaining the procedure to the patients, the nodule of interest was palpated and under aseptic precautions, Fine needle aspiration was performed, material aspirated and smeared onto clean glass slides. Smears were wet fixed using 95\% ethyl alcohol for Haematoxylin and eosin (H\&E) stain and Papanicalaou stain, and air dried for Leishman stain.

The histopathological specimens when available were fixed overnight in $10 \%$ formalin, processed using automatic tissue processor andstained with routine $\mathrm{H} \& \mathrm{E}$ stain. The cytological and histopathological slides were studied under light microscope, analyzed and correlated. Exclusion criteria included all cases where the aspirate was inadequate and or smears were acellular/hemorrhagic. Cytological features were analysed and was correlated with histopathological diagnosis whenever excised salivary gland specimens were available. Sensitivity, specificity, positive predictive value, negative predictive value and diagnostic accuracy of FNAC relative to the final diagnosis were calculated.

\section{RESULTS}

The cytomorphological features of salivary gland lesions were studied along with age, sex and site distribution. A total of 150 cases were included in the study. Histopathology correlation was available for 52 cases. The patient's age ranged from $10-82$ years with mean age of $41.2 \pm 16$ years. Maximum number of cases, $39(26 \%)$ cases belonged to the age group of $31-40$ years. Out of 150 cases, majority of the 80 patients were males accounting for $53.33 \%$ and females were 70 $(46.67 \%)$ with male to female ratio of 1.14:1.

In the present study parotid gland was the most commonly affected. $110(73.34 \%)$ patients were found to have parotid lesions followed by 35 (23.33\%) patients who had lesions in submandibular gland and 5 $(3.33 \%)$ patients had lesions in minor salivary glands. Parotid gland was commonest involved gland in both males and females, i.e $60(75 \%)$ and $50(71.4 \%)$. Out of 150 patients, majority of $90(60 \%)$ patients had lesions on the right side followed by $52(34.67 \%)$ patients who had lesions on the left side and $8(5.33 \%)$ patients had bilateral lesions.

Out of 150 cases, majority of the $61(40.67 \%)$ cases were reported as pleomorphic adenoma, followed by $34(22.67 \%)$ cases reported as chronic sialadenitis, 14 $(9.33 \%)$ cases were mucoepidermoid carcinoma, $13(8.67 \%)$ were sialadenosis, $10(6.66 \%)$ cases were acute sialadenitis, $7(4.66 \%)$ cases were Warthin's tumour, 4(2.66\%) cases reported as cystic lesion, 2 $(1.33 \%)$ cases were adenoid cystic carcinoma and 1 $(0.67 \%)$ case each was granulomatous sialadenitis, lymphoepithelial cyst, mucocele, basal cell adenoma and carcinoma Ex pleomorphic adenoma (Table-1).

Table-1: Lesions diagnosed by FNAC

\begin{tabular}{|l|c|c|}
\hline \multicolumn{1}{|c|}{ DIAGNOSIS } & NO OF PATIENTS & $\begin{array}{c}\text { PERCENTAGE } \\
(\mathbf{\%})\end{array}$ \\
\hline Acute sialadenitis & 10 & 6.66 \\
\hline Chronic sialadenitis & 34 & 22.67 \\
\hline Granulomatous sialadenitis & 1 & 0.67 \\
\hline Cystic lesion & 4 & 2.66 \\
\hline Lymphoepithelial cyst & 1 & 0.67 \\
\hline Mucocele & 1 & 0.67 \\
\hline Sialadenosis & 13 & 8.67 \\
\hline Pleomorphic adenoma & 61 & 40.67 \\
\hline Basal cell adenoma & 1 & 0.67 \\
\hline Warthin's tumour & 7 & 4.66 \\
\hline Mucoepidermoid carcinoma & 14 & 9.33 \\
\hline Adenoid cystic carcinoma & 2 & 1.33 \\
\hline $\begin{array}{l}\text { Carcinoma Ex pleomorphic } \\
\text { adenoma }\end{array}$ & 1 & 0.67 \\
\hline TOTAL & $\mathbf{1 5 0}$ & $\mathbf{1 0 0}$ \\
\hline
\end{tabular}


On FNAC, the lesions were broadly categorized into non neoplastic and neoplastic lesions and majority of cases, $86(57.33 \%)$ were neoplastic lesions and $64(42.67 \%)$ were non neoplastic lesions. Among the 86 neoplastic lesions, majority of $69(80.23 \%)$ cases were benign neoplastic lesions and $17(19.77 \%)$ were malignant neoplastic lesions. And out of 69 benign neoplastic lesions, 61(88.4\%) patients had pleomorphic adenoma followed by $7(10.15 \%)$ patients of Warthin's tumour and $1(1.45 \%)$ was basal cell adenoma. The microscopic features of all cases of pleomorphic adenoma showed high cellularity comprising of poorly cohesive ductal epithelial cells in branching sheets and in clusters along with dense magenta coloured fibrillary chondromyxoid matrix. Many bare nuclei noted in the background. Mainly myoepithelial cells were seen which were ovoid, plasmacytoid or spindle, with abundant well-defined cytoplasm and round to ovoid nuclei with bland nuclei and smooth nuclear membrane (Fig-1). Many myoepithelial cells were also seen embedded in stromal matrix. Occasional oncocytic, sebaceous and squamous cells were seen. Fig 2 shows Warthins tumour comprising of sheets of bland oncocytic cells in singles and in cohesive, monolayered sheets along with plenty of lymphoid cells. Background showed amorphous and granular debris along with mucus. One case showed plenty of murky fluid with only few oncocytic cells.



Fig-1: Pleomorphic adenoma. a) Fibrillar fibromyxoid stroma staining brightly red/magenta (Leishman stain, 4X). b) Plasmacytoid myoepithelial (hyaline-cell) pattern (Pap, 40X). c) Spindle shaped myoepithelial cells (H\&E, 40X)

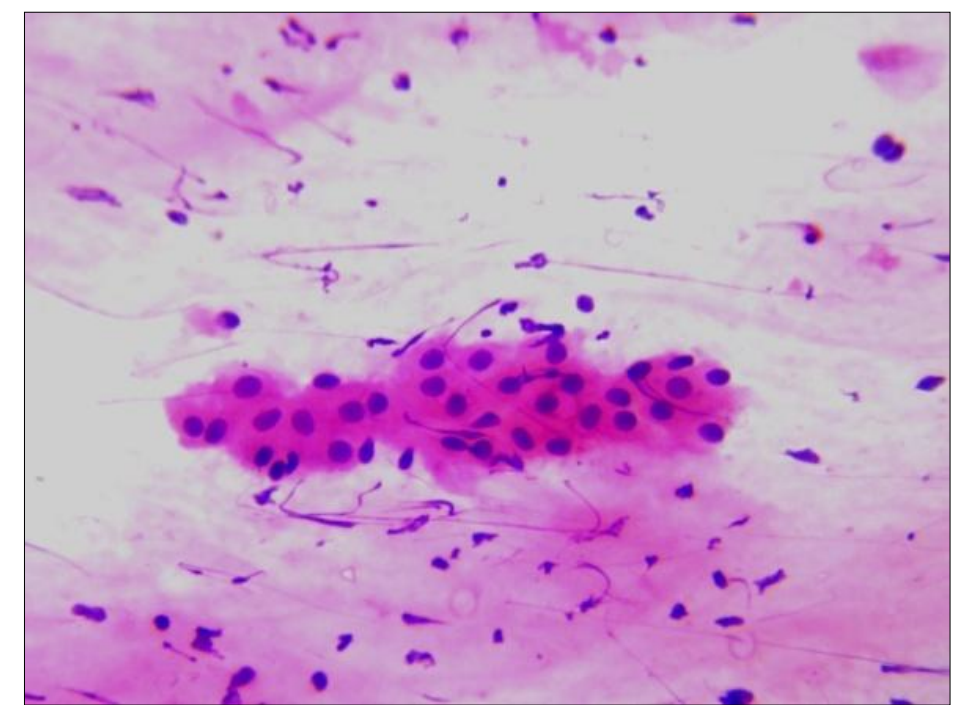

Fig-2: Warthin's tumor- showing prominent oncocytic epithelial cells with abundant deeply eosinophilic cytoplasm arranged in sheets (H\&E, 40X) 
Out of 17 malignant neoplastic lesions, majority of $13(76.47 \%)$ cases were low grade Mucoepidermoid carcinoma, 1(5.88\%) was high grade mucoepidermoid carcinoma, 2(11.77\%) were adenoid cystic carcinoma and $1(5.88 \%)$ was Carcinoma Ex pleomorphic adenoma. The mucoepidermoid carcinoma cases showed sparse cellularity with few clusters and sheets of epithelial cells and small streams of cells within mucus. These cells were predominantly intermediate cells with few muciphages and occasional squamous epithelial cells. These cells had relatively bland nuclei and some cells showed prominent nucleoli.
Background was dirty with admixture of mucus, debris along with few inflammatory cells and macrophages (Fig-3). Two cases were reported as adenoid cystic carcinoma showed moderate to highly cellular with tumour cells arranged in multilayered sheets and clusters. These cells had high $\mathrm{N}$ : $\mathrm{C}$ ratio with round to oval hyperchromatic nuclei with coarse nuclear chromatin, prominent nucleoli and scant cytoplasm. Some of the cells showed nuclear moulding. Hyaline spherical globules were seen adherent to the tumor cells (Fig-4).



Fig-3: Mucoepidermoid carcinoma : a) A large mucus-producing cell in a 'dirty' background of mucus, debris and few inflammatory cells $(\mathrm{H} \& \mathrm{E}, 40 \mathrm{X})$ b) Muciphages with mucinous material in the background (H\&E, 40X), c) Moderately cellular smears showing cluster of intermediate cells with bland nuclei and epidermoid cells (H\&E, 40X)

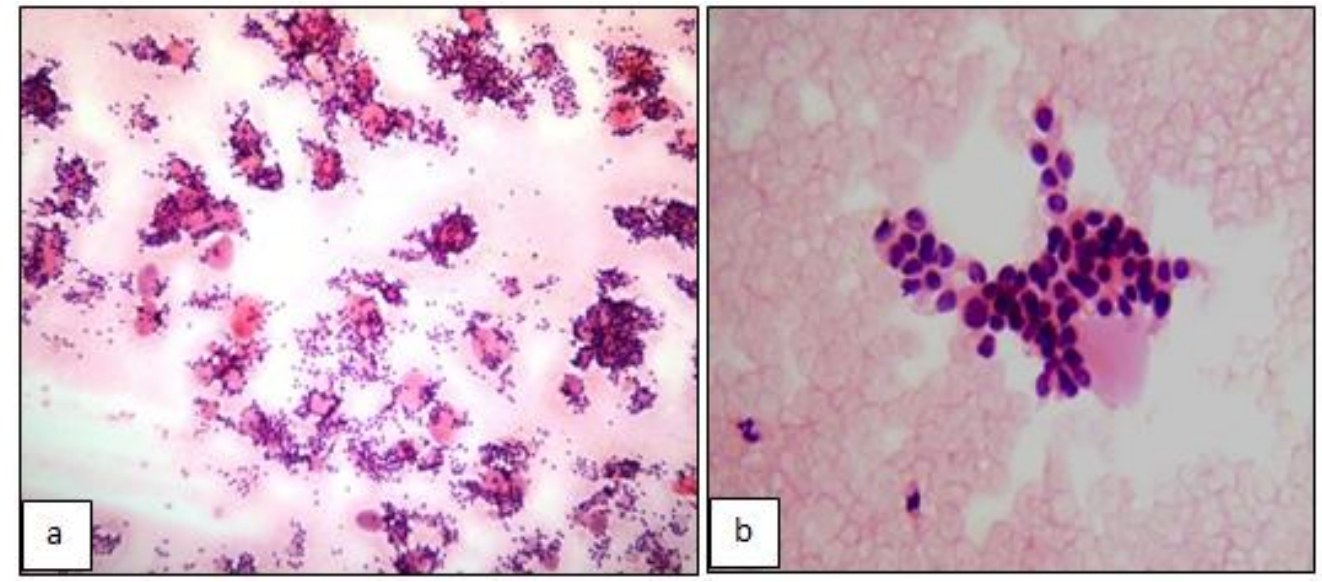

Fig-4: Adenoid cystic carcinoma- a) Highly cellular smears with dispersed epithelial cells with hyperchromatic nuclei adhering to hyaline stromal globule $(\mathrm{H} \& \mathbf{E}, 4 \mathrm{X})$ b) Ill-defined clusters of small, basaloid cells with hyperchromatic nuclei 
Among 64 non neoplastic lesions, majority of patients, 34(53.13\%) were reported as chronic sialadenitis, followed by $13(20.31 \%)$ cases which was reported assialadenosis, $10(15.63 \%)$ cases as acute sialadenitis, $4(6.25 \%)$ cases were reported as cystic lesion and $1(1.56 \%)$ as granulomatous sialadenitis, lymphoepithelial cyst and mucocele respectively (Table1).The chronic sialadenitis cases showed high cellularity comprising predominantly of lymphocytes, along with few histiocytes and occasional neutrophils. Clusters of ductal epithelium with few acinar cells were seen (Fig-5).

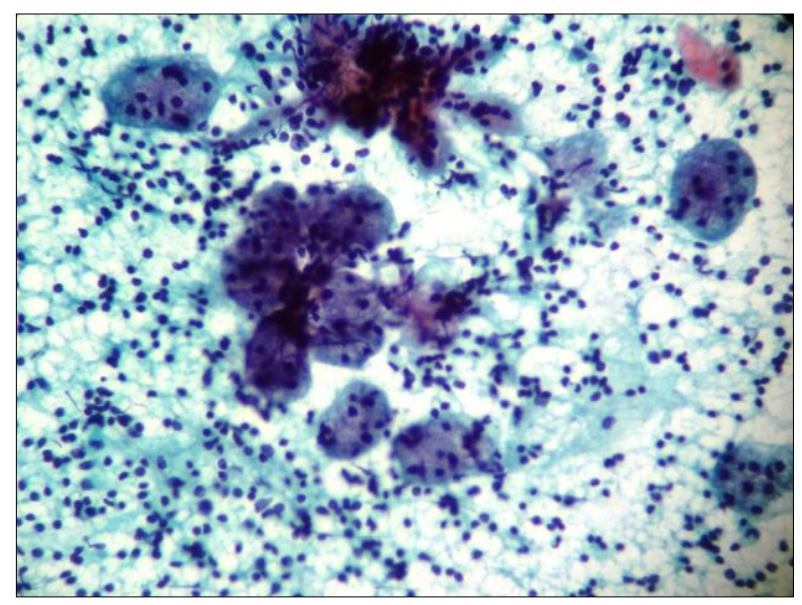

Fig-5: Chronic sialadenitis - Salivary gland acini in a background of chronic inflammatory cells (Pap, 40X)

Out of the 52 cases available for histopathology, 44 cases were concordant and 8 cases were discordant with FNAC diagnosis (Table-2). Among the total 31 cases reported as benign neoplastic lesions on HPE, 30 cases were confirmed as benign neoplasms and only one case was a malignant lesion. Twenty nine cases of pleomorphic adenoma had histopathological correlation with 27 of these were confirmed. One case of basal cell adenoma and one case of benign myoepithelioma on histopathology were called as pleomorphic adenoma on HPE, though all were confirmed as benign neoplasms. Two cases were reported as Warthin's tumour on FNAC, one case was confirmed as Warthin's tumour on HPE and the other case was low grade mucoepidermoid carcinoma.

Among 14 cases of MEC on FNAC, histopathology was available for 10 cases, out of which nine were confirmed by HPE and one case turned out to be moderately differentiated squamous cell carcinoma on HPE. One case diagnosed as adenoid cystic carcinoma on FNAC was low grade cribriform adenocarcinoma on HPE. One case of carcinoma Ex pleomorphic adenoma was confirmed on HPE (Table2). Among 12 cases of malignant lesions on FNAC, however all were malignant lesions on HPE.

Among the 8 discordant cases, four cases i.e, basal cell adenoma, benign myoepithelioma, moderately differentiated squamous cell carcinoma and low grade cribriform adenocarcinoma the management of patients did not change. But in the remaining 4 cases management changed.

Table-2: Cytohistological Correlation of Salivary Gland Lesions

\begin{tabular}{|c|c|c|c|c|c|}
\hline & \multirow{2}{*}{$\begin{array}{l}\text { Cytological Diagnosis } \\
\text { (FNAC diagnosis) }\end{array}$} & \multirow{2}{*}{$\begin{array}{l}\text { No Of Cases For } \\
\text { Which } \\
\text { Histopathology } \\
\text { Available } \\
\end{array}$} & \multirow[t]{2}{*}{ Histopathological Diagnosis } & \multicolumn{2}{|c|}{ HISTOPATHOLOGY } \\
\hline & & & & CONCORDANT & DISCORDANT \\
\hline \multirow{4}{*}{ 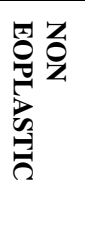 } & Acute sialadenitis & 1 & Acute sialadenitis-1 & 1 & 0 \\
\hline & Chronic sialadenitis & 5 & $\begin{array}{l}\text { Chronic sialadenitis-4 } \\
\text { Pleomorphic adenoma-1 }\end{array}$ & 4 & 1 \\
\hline & Cystic lesions & 2 & $\begin{array}{l}\text { Salivary duct cyst }-1 \\
\text { Mucoepidermoid carcinoma }-1\end{array}$ & 1 & 1 \\
\hline & Mucocele & 1 & Mucoepidermoid carcinoma - 1 & 0 & 1 \\
\hline \multirow{2}{*}{ 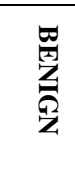 } & Pleomorphic adenoma & 29 & $\begin{array}{l}\text { Pleomorphic adenoma }-27 \\
\text { Basal cell adenoma }-1 \\
\text { Benign myoepithelioma }-1\end{array}$ & 27 & 2 \\
\hline & Warthin's tumour & 2 & $\begin{array}{l}\text { Warthin's tumour }-1 \text { Low grade } \\
\text { mucoepidermoid carcinoma }-1\end{array}$ & 1 & 1 \\
\hline \multirow{4}{*}{ 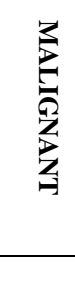 } & $\begin{array}{l}\text { Mucoepidermoid } \\
\text { carcinoma }\end{array}$ & 10 & $\begin{array}{l}\text { Mucoepidermoid carcinoma }-9 \\
\text { Moderately differentiated squamous } \\
\text { cell carcinoma- } 1\end{array}$ & 9 & 1 \\
\hline & $\begin{array}{c}\text { Adenoid cystic } \\
\text { carcinoma }\end{array}$ & 1 & $\begin{array}{l}\text { Low grade cribriform } \\
\text { adenocarcinoma }-1\end{array}$ & 0 & 1 \\
\hline & $\begin{array}{c}\text { Carcinoma Ex } \\
\text { pleomorphic adenoma }\end{array}$ & 1 & $\begin{array}{l}\text { Carcinoma Ex pleomorphic } \\
\text { adenoma- } 1\end{array}$ & 1 & 0 \\
\hline & TOTAL & 52 & & $44(84.62 \%)$ & $8(15.38 \%)$ \\
\hline
\end{tabular}


Out of 150 cases in present study, histopathology was available for 52 cases, and among which 43 cases were true positive for neoplastic lesions on FNAC. The sensitivity, specificity of FNAC for diagnosing neoplastic salivary gland lesions were $93.48 \%$ and $100 \%$. Positive predictive value, negative predictive value and diagnostic accuracy of FNAC for diagnosing neoplastic salivary gland lesions were $100 \%, 66.67 \%$ and $94.23 \%$ respectively.

\section{DISCUSSION}

Salivary gland tumours comprise $3 \%$ to $6 \%$ of all head and neck neoplasms in adults with an incidence of 1 to 3 per 100.000 people per year [4, 13]. Fine needle aspiration cytology (FNAC) of the salivary gland is a widely used and commonly accepted, sensitive and specific technique in the diagnosis of both neoplastic and non-neoplastic lesions of the salivary gland $[1,2]$. This has proved to be a very important diagnostic tool in the diagnosis of salivary gland lesions, mainly due to its safe procedure, costeffectiveness, lower rate of complications and aids the clinician in therapeutic management [14]. In the present study, there were total of 150 cases and maximum number of the cases was in the age group of 31-40 years (26\%), similar observations were made by Singh A et $a l$. in which maximum number of patientsbelonged to age group of 31-40 years [15].

The present study showed a male preponderance with male to female ratio of 1.14:1 and was comparable with other studies [16-18]. Parotid gland was the most commonly involved seen in $110(73.34 \%)$ of patients, followed by $35(23.33 \%)$ in submandibular gland and $5(3.33 \%)$ in minor salivary glands, correlating very well with other studies [18]. Similar to other studies[19] we found that out of 150 patients, right sided dominance with 90 cases $(60 \%)$ followed by 52 cases $(34.67 \%)$ with left side lesions and $8(5.33 \%)$ patients had bilateral involvement. Neoplastic lesions were more common than nonneoplastic lesions in the present study, similar to other studies $[15,17,18,20]$. In the present study, benign group constituted $80.23 \%$ of cases and malignant group constituted $19.77 \%$ of the cases, which was similar to other studies [15-18, 20].

Among the benign neoplastic lesions, Pleomorphic adenoma was the commonest benign neoplasm accounting for $40.66 \%$ of the cases, followed by Warthins tumour(4.67\%). Similar observation was made by studies done by Upasana $\mathrm{P}$ et al. Gandhi $\mathrm{S}$ et al. Singh A et al. and Khandekar et al. [15-18, 20]. However Jain C et al. had 20\% of Pleomorphic adenoma cases and $1.42 \%$ each of basal cell adenoma and oncocytoma in his study [16]. Among the benign group, pleomorphic adenoma (61 cases) was the commonest benign neoplasm, similar to other studies [16-18].
In our study, among the malignant neoplastic lesions, Mucoepidermoid carcinoma (MEC) was the commonest malignant neoplasm accounting for $9.3 \%$ of the all cases, followed by Adenoid cystic carcinoma $(1.3 \%)$. Similar observation was made by studies done by Gandhi SH et al. Khandekar et al. Jain C et al. and Upasana P et al. [16-18, 20]. However study done by Singh A et al. found that adenoid cystic carcinoma $(8.33 \%)$ as the commonest malignant neoplasm followed by MEC (4.16\%)[15].

Among the non-neoplastic lesions, chronic sialadenitis was the commonest non neoplastic lesion accounting for $22.67 \%$ of the cases, followed by sialadenosis $(8.6 \%)$ and acute sialadenitis $(6.6 \%)$. This finding was similar to other studies who also found chronic sialadenitis as the commonest non neoplastic lesion [16-18].

Among the 64 non neoplastic cases, 9 of these cases had histopathological correlation. One case of acute sialadenitis was concordantly diagnosed as acute sialadenitis. Five out of 34 chronic saialadenitis cases had histopathological correlation. Four cases were correctly diagnosed as chronic sialadenitis on histopathology, but one case was diagnosed as pleomorphic adenoma on histology. Comparatively young age of both the patients with shorter duration of the swellings and presence of plenty of inflammatory cells in the reviewed smears could be the causes for this misdiagnosis. Repeat aspirations after control of infection with careful history taking were necessary for correct diagnosis. In the present study, there were 4 cases of cysts, which were diagnosed by FNAC. Only 2 cases were available for histopathological correlation. One was concordantly diagnosed as salivary duct cyst, and the other was discordantly diagnosed as Mucoepidermoid carcinoma. The FNAC slides were reviewed, which showed plenty of cyst macrophages and degenerated epithelial cells against a mucoid background. There were no intermediate, mucus or squamoid cells. This may be due to a sampling error where the needle might have hit only the cystic area. Repeated aspirations, particularly aspirations from the remnant swelling after draining off the contents of the cystic swelling, mayhelp in minimizing these types of errors. When the tumour is cystic and the aspiration yields only mucous material, a diagnosis of MEC may be missed. One case of mucocele was wrongly diagnosed as mucoepidermoid carcinoma on histopathology. Mukunyadzi stated that in any cystic lesions, the residual mass, following initial aspiration, should be reaspirated and careful search for a mixture of mucous cells and intermediate cells should avoid the misdiagnosis of mucoepidermoid carcinoma [21]. AlKhafaji et al. stated that most common false negative interpretation of mucoepidermoid carcinoma is due to dilution of tumor cells by mucoid fluid and bland looking intermediate cells [22]. The most probable cause of error in our case was due to fluid dilution of 
tumor cells and failure to observe the intermediate cells. This could be avoided by reaspiration of the residual mass and careful search for mucous and intermediate cells. The cystic aspirates should be interpreted with caution.

Among the 61 cases $(40.67 \%)$ diagnosed as Pleomorphic adenoma cytologically, 29 cases were available for histopathological correlation, out of which 27 were concordantly diagnosed. The commonest features seen in all the cases were epithelial and mesenchymal components including fibrous, mucinous, myxochondroid and chondroid tissues. 2 cases were discordantly diagnosed as basal cell adenoma and myoepithelioma respectively. The FNAC slides of both these discordant cases were reviewed and both highly cellular smears with scant stromal elements and were mistakenly diagnosed as PA. Practically, this discordance was of minor importance, since the surgical treatment was similar in both the cases. Seven cases diagnosed as Wathins tumour(WT) by FNAC. 2 cases were available for histopathological correlation, of which one was discordantly diagnosed as mucoepidermoid carcinoma. The slides reviewed showed a combination of oncocytes, lymphoid tissues and cystic macrophages, so this was wrongly diagnosed as WT. The absence of epidermoid cells, intermediate cells and mucus cells against a dirty necrotic background resulted in a failure to diagnosemucoepidermoid carcinoma. So there were 3 false positive in benign group.
A total of 14 cases were diagnosed cytologically as mucoepidermoid carcinoma. Out of which 9 were confirmed as MEC. All of these nine cases showed all the 3 cellular components including epidermoid cells, intermediate cells and mucous cells in a necrotic mucoid background. One case was wrongly diagnosed as MEC on FNAC and was moderately differentiated squamous cell carcinoma on histopathology. FNAC slides were reviewed, which showed sheets of squamoid cells which was mistaken for epidermoid component of MEC. Two cases of Adenoid cystic carcinoma were reported cytologically in an 82 year old male and another was reported in a 53 year old female, one presenting with hard palate swelling and the other as a parotid mass. One case available for histopathological correlation showed Low grade cribriform cystadenocarcinoma. In the present case, the FNAC smears showed many hyaline globules with small basaloid cells mimicking adenoid cystic carcinoma. Only one case was diagnosed as Carcinoma ex pleomorphic adenoma cytologically. The smears studied showed epithelial cell clusters which revealed a prominent nuclear enlargement and atypia with clusters of benign epithelial cells and myxoid stroma. Histopathological correlation later confirmed it.

The present study showed sensitivity of $93.48 \%$ and specificity of $100 \%$ which was similar to the observations made by other studies (Table 3)[1518]. Diagnostic accuracy of $94.23 \%$ was observed in our study which was similar to study done by Jain C et al. (Diagnostic accuracy - 93\%) [16].

Table-3: Sensitivity, specificity and diagnostic accuracy of salivary gland lesions with various other studies

\begin{tabular}{|l|l|l|l|l|}
\hline Studies & Total No Of Cases & Sensitivity (\%) & Specificity (\%) & Diagnostic Accuracy (\%) \\
\hline Upasana P et al. & 120 & $89.29 \%$ & $91.67 \%$ & $86.21 \%$ \\
\hline Jain C et al. & 70 & $92.93 \%$ & $100 \%$ & $93 \%$ \\
\hline Gandhi S et al. & 90 & $97.5 \%$ & $100 \%$ & - \\
\hline Singh A et al. & 96 & $76.9 \%$ & $97.1 \%$ & - \\
\hline Khandekar M et al. & 70 & $94-54 \%$ & $80-95 \%$ & - \\
\hline Present study & 150 & $93.48 \%$ & $100 \%$ & $94.23 \%$ \\
\hline
\end{tabular}

\section{CONCLUSION}

FNAC of the salivary gland is a safe and reliable technique in the primary diagnosis of salivary gland lesions and could effectively classify salivary gland lesions into non neoplastic and neoplastic lesions. FNAC is a very valuable diagnostic adjuvant to the clinician in the diagnosis of various tumors and can be used preoperatively to avoid unnecessary surgery and discomfort associated with open biopsy. Though there are several diagnostic pitfalls, fine needle aspiration should always be encouraged for initial assessment of all salivary gland swellings. FNAC of the salivary gland tumours showed that it is advantageous for both the patients and the clinicians because of its immediate results, accuracy lack of complications and its economy.

\section{REFERENCES}

1. Kala, C., Kala, S., \& Khan, L. (2019). Milan system for reporting salivary gland cytopathology: An experience with the implication for risk of malignancy. Journal of cytology, 36(3), 160.

2. Fernandes, H., D'souza, C. R., Khosla, C., George, L., \& Katte, N. H. (2014). Role of FNAC in the preoperative diagnosis of salivary gland lesions. Journal of clinical and diagnostic research: JCDR, 8(9), FC01.

3. Rohilla, M., Singh, P., Rajwanshi, A., Gupta, N., Srinivasan, R., Dey, P., \& Vashishta, R. K. (2017). Three-year cytohistological correlation of salivary gland FNA cytology at a tertiary center with the application of the Milan system for risk stratification. Cancer cytopathology, 125(10), 767775. 
4. Schindler, S., Nayar, R., Dutra, J., \& Bedrossian, C. W. (2001, May). Diagnostic challenges in aspiration cytology of the salivary glands. In Seminars in diagnostic pathology (Vol. 18, No. 2, pp. 124-146).

5. Orell, S. R. (1995). Diagnostic difficulties in the interpretation of fine needle aspirates of salivary gland lesions: the problem revisited. Cytopathology, 6(5), 285-300.

6. Young, J. A. (1994). Diagnostic problems in fine needle aspiration cytopathology of the salivary glands. Journal of clinical pathology, 47(3), 193.

7. Kocjan, G., \& Shah, K. A. Churchill Living stone. Edinburgh; 2010. Salivary glands. Diagnostic Cytopathology, 231-52.

8. Jain, R., Gupta, R., Kudesia, M., \& Singh, S. (2013). Fine needle aspiration cytology in diagnosis of salivary gland lesions: A study with histologic comparison. Cytojournal, 10.

9. Kocjan, G., Ramsay, A., Beale, T., \& O'Flynn, P. (2009). Head and neck cancer in the UK: what is expected of cytopathology?. Cytopathology, 20(2), 69-77.

10. Chakrabarti, S., Bera, M., Bhattacharya, P. K., Chakrabarty, D., Manna, A. K., Pathak, S., \& Maiti, K. (2010). Study of salivary gland lesions with fine needle aspiration cytology and histopothology along with immunohistochemistry. Journal of the Indian Medical Association, 108(12), 833-836.

11. Henry-Stanleys, M. J., Beneke, J., Bardales, R. H., \& Stanley, M. W. (1995). Fine-needle aspiration of normal tissue from enlarged salivary glands: sialosis or missed target?. Diagnostic cytopathology, 13(4), 300-303.

12. Stanley, M. W., Bardales, R. H., Beneke, J., Korourian, S., \& Stern, S. J. (1996). Sialolithiasis: Differential diagnostic problems in fine-needle aspiration cytology. American journal of clinical pathology, 106(2), 229-233.

13. Ersöz, C., Uguz, A. H., Tuncer, Ü., Soylu, L., \& Kiroglu, M. (2004). Fine needle aspiration cytology of the salivary glands: a twelve years' experience. Aegean Pathol J, 1, 51-6.

14. Qizilbash, A. H., Sianos, J., Young, J. E., \& Archibald, S. D. (1985). Fine needle aspiration biopsy cytology of major salivary glands. Acta cytologica, 29(4), 503-512.

15. Singh, A., Haritwal, A., \& Murali, B. M. (2011). Correlation between cytology and histopathology of the salivary glam. The Australasian medical journal, 4(2), 66.

16. Jain, C. (2013). Fine needle aspiration cytology of salivary gland lesions: a study of 70 cases. Int $J$ Med Pharm Sci, 3(07).

17. Gandhi, S. H., Purohit, T. M., Purohit, M. B., Jethwani, D., \& Vidja, M. (2013). FNAC Diagnosis of salivary gland lesions with histopathological correlation. NJIRM, 4(3), 70-7.

18. Upasana, P., Ina, S., \& Hansa, G. (2015). A cytological and histological comparative study of salivary gland lesions at tertiary health care centre. Int J Biomed Adv Res, 6(6), 470-4.

19. Orell, S. R. (1995). Diagnostic difficulties in the interpretation of fine needle aspirates of salivary gland lesions: the problem revisited. Cytopathology, 6(5), 285-300.

20. Khandekar, M. M., Kavatkar, A. N., Patankar, S. A., Bagwan, I. B., Puranik, S. C., \& Deshmukh, S. D. (2006). FNAC of salivary gland lesions with histopathological correlation. Indian Journal of Otolaryngology and Head and Neck Surgery, 58(3), 246-248.

21. Mukunyadzi, P. (2002). Review of fine-needle aspiration cytology of salivary gland neoplasms, with emphasis on differential diagnosis. Pathology Patterns Reviews, 118(suppl_1), S100-S115.

22. Al-Khafaji, B. M., Nestok, B. R., \& Katz, R. L. (1998). Fine-needle aspiration of 154 parotid masses with histologic correlation: ten-year experience at the University of Texas MD Anderson Cancer Center. Cancer Cytopathology: Interdisciplinary International Journal of the American Cancer Society, 84(3), 153-159. 